\section{Dispersion of Sound Velocity in Liquids}

As is now well known ${ }^{1}$, the spectral character of monochromatic light scattered by many liquids exhibits an observable change as the result of such scattering; an instrument of sufficiently high resolving power, for example, a Fabry-Perot étalon ${ }^{2}$, indicates the presence of Doppler-shifted components on either side of the main radiation. From this we are able to infer that sound waves of very high frequency represent a considerable part of the energy of thermal agitation in such liquids. The frequency of the sound-waves actually revealed by this method depends on the wave-length of the incident light, the angle of scattering and the liquid employed; in most actual cases, it lies within the frequency range $1,000-10,000$ megacycles per second.

It is a question of considerable importance, whether these spontaneously existing sound-waves of thermal origin of very high frequencies ('hyper-sonic waves'), have velocities of propagation differing appreciably from those of lower frequencies (audio-waves and ultra-sonic waves) capable of being produced artificially by mechanical or electro-acoustic methods. The sound velocities within the ultra-sonic range $(<100$ mega-cycles $)$ can be measured with high precision (Hiedemann ${ }^{3}$ and Parthasarathy ${ }^{4}$, etc.). For the determination of the hypersonic velocity, we have to depend on the magnitude of the Dopplershifts as observed interferometrically, the measurements of which are, however, liable to serious errors owing to $(a)$ the angular width of the scattered beam, (b) the intrinsic breadth of the Doppler component, and $(c)$ the imperfect monochromatism of the incident radiation, including especially the hyperfine structure satellites. The third source of error is particularly serious, as the satellites are intense and by their superposition shift the apparent position of the Doppler components. An examination of the published literature shows that none of the measurements reported so far has taken account of the sources of error sufficiently to enable any definite conclusions to be drawn from them.

TABLE 1.

\begin{tabular}{|c|c|c|c|}
\hline Liquid & $\begin{array}{c}\text { Observed } \\
\text { Doppler shift } \\
\left(\mathrm{cm} \text { - }^{-1}\right)\end{array}$ & $\begin{array}{c}\text { Velocity in metres/second } \\
\text { 'Hyper-sonic' } \\
\text { frequency } \\
5 \cdot 0 \times 10^{9}\end{array}$ & $\begin{array}{c}\text { 'Ultra-sonic' } \\
\text { frequency } \\
7 \cdot 32 \times 10^{6}\end{array}$ \\
\hline $\begin{array}{c}\text { Carbon tetra- } \\
\text { chloride } \\
\text { Acetone }\end{array}$ & $\begin{array}{c}0 \cdot 261 \\
0 \cdot 221\end{array}$ & $\begin{array}{c}1070 \pm 25 \\
978 \pm 25\end{array}$ & $\begin{array}{c}928 \pm 1 \\
1205 \pm 1\end{array}$ \\
\hline
\end{tabular}

The subject has been taken up afresh by me, at the suggestion of Sir C. V. Raman, and systematic efforts have been made to eliminate the sources of error mentioned above by choosing the experimental conditions suitably. By using a low-density and cathode-cooled mercury are lamp, and by a proper selection of the radiation used and of the invar distance piece separating the plates of the étalon employed, with reference to the sound velocity in the liquid under investigation, it has been found possible to eliminate the errors and obtain dependable results.

The programme now on hand includes numerous liquids ; it will be sufficient here to report the results for carbon tetrachloride and acetone, which have stood the test of careful repetition and scrutiny.

It is interesting to note that in carbon tetrachloride the hyper-sonic velocity is definitely greater than the ultra-sonic velocity, while in acetone the reverse is the case.

Department of Physics,

\section{B. V. Raghavendra Rao.}

Indian Institute of Science, Bangalore. April 10.

${ }^{1}$ Brillouin, L., Ann. Phys., 17, 88 (1922). Gross, E., Nature, 126, $201,400,603(1930)$.

${ }_{2}$ Raghavendra Rao, B. V., Proc. Ind. Acad. Sci., A, 1, 261, 473, ${ }^{2}$ Raghavendra Rao, B. V., Proc. Ind. A
765 (1934); 2, 236 (1935); 3, 607 (1936).

${ }^{3}$ Hiedemann, E., and Bachem, Z. Phys., 94, 68 (1935).

"Parthasarathy, S., Proc. Ind. Acad. Sci., A, 2, 497 (1935).

\section{An Effect of Rectified Current from a Tunger Valve} upon the Electrolytic Separation of Heavy Water

A RATHER low yield of the heavy water obtained with the usual method of electrolysis, using the singlephase full-wave Tunger valve rectifier, led us to investigate the cause of loss of the heavy water. Besides a good deal of loss through evaporation and spraying, and possibly a loss arising from an exchange reaction occurring at the electrode, the rectified current employed may have been also a contributing factor to the loss.

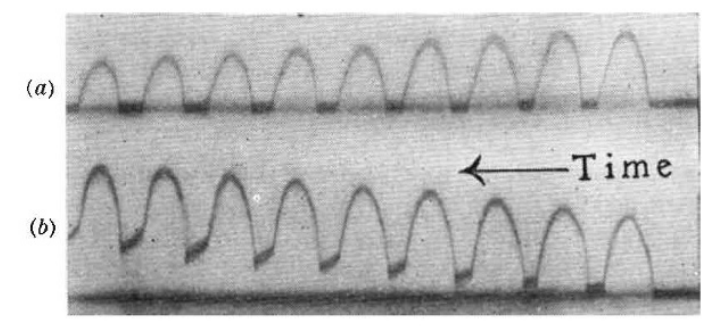

Fig. 1.

With this latter view in mind, the following experiments were performed. Two identical cells in a closed form with nickel electrodes, which were so constructed as to make a loss from evaporation and spraying entirely negligible, were employed. In each of these two cells was placed an equal amount of the electrolytes (40 c.c.) with 1 per cent $\mathrm{D}_{2} \mathrm{O}$ content. To one cell was supplied the direct current, to the other the rectified current. The two cells were independently connected with a Wood discharge tube. The intensity of the $D \gamma$ line in the Balmer series was observed from the water remaining in the cell, simultaneously with the decrease of the volume of the electrolyte. The result after the exposure of one minute showed that on the D.C. side the D $\gamma$ line appeared at one ninth the initial volume, whereas on the rectified current side the same intensity of Dr line appeared at one twenty-seventh the initial volume.

The effect was also investigated with the oscillograph, using this time fifteen cells actually employed for the production of the heavy water. The result showing the variation of current and voltage with the time immediately after the rectified current was supplied are shown in Fig. 1, where $a$ shows that the current passing through the cell becomes smaller with the period of the pause becoming greater; and $b$ shows that the back E.M.F. reaches the half-value 